\title{
Imagens fílmicas infantes: espaços de incidência inventiva
}

\author{
Vivien Kelling Cardonetti* \\ Marilda Oliveira de Oliveira**
}

\begin{abstract}
Resumo
Este artigo é parte de uma pesquisa de doutorado em Educação e Artes na Universidade Federal de Santa Maria (UFSM) e propõe produzir diferentes fluxos de pensamentos a partir de três encontros fílmicos em que a criança se faz presente. Intenciona dar atenção àquilo que tem a potência de afetar (SPINOZA, 2010) e inquietar, possibilitando a produção de diferentes arranjos e tessituras em relação à educação. As problematizações suscitadas a partir do cruzamento dos espaços de incidência inventiva com a potência infante (DELEUZE, 2006) nos filmes 'Los colores de las flores', A Invenção de Hugo Cabret' e 'O Balão Branco', potencializou o esboço de outras possibilidades de atuar, simulando diferentes modos de ser e desenhando singulares formas de vivenciar a docência.

Palavras-chave: Potência de agir; Encontro fílmico; Potência infante.
\end{abstract}

\section{Infant filmic images: spaces of inventive incidence}

\begin{abstract}
This paper is part of a $\mathrm{PhD}$ research in Education and Arts at Federal University of Santa Maria (UFSM), and proposes to produce different thought fluxes through three filmic encounters in which children are present. It aims to draw attention to what has the potency to affect (SPINOZA, 2010) and disturb, making the production of different arrangements and weavings related to Education. The problematization created by the interweaving between the spaces of inventive incidence and the infant potency (DELEUZE, 2006) in the movies 'Los colores de las flores', 'A Invenção de Hugo Cabret', and 'O Balão Branco', has potentialized the outline of other possibilities for acting, simulating different ways of being and drawing singular forms of experiencing teaching. Keywords: Acting potency; Filmic encounter; Infant potency.
\end{abstract}

\section{Possibilidades de encontros}

Nos diferentes percursos da nossa vida, somos surpreendidos com encontros e por eles somos desafiados a efetuar cruzamentos, composições e rupturas. Quando Deleuze (19881989 , p. 11) coloca "não estou certo de ter um encontro, mas parto à espreita", faz-nos pensar que os encontros nem sempre acontecem, algumas vezes eles nos escapam, justamente por não serem evidentes. É necessário que estejamos receptivos aos convites que eles nos endereçam.

Ao estarmos atentos aos encontros, passamos a ser "um observador sensível às sutilezas da vida cotidiana" (VAN MANEN, 2003, p. 47). O desafio talvez esteja em descansar o olhar em cada um dos encontros para que possamos nos colocar em posição de aprender com eles, deixando-nos inundar pelas ocorrências que não prevemos, que não conhecemos, que nos causam temor, que nos desafiam a pensar diferente e que fazem tombar nossas certezas e dogmas.

Os encontros fortuitos lidam com a imprevisibilidade, com o não conhecido, com aquilo que não pode ser antecipado, causando o *Endereço eletrônico: vicardonetti@gmail.com

***Endereço eletrônico: marildaoliveira27@ gmail.com estranhamento. E é justamente esse encontro surpreendente, movediço e oscilante que assegura a premência daquilo que é pensado. Quando estamos à mercê do inesperado em um encontro, distanciamo-nos da realidade costumeira e da referência cognitiva que nos causam segurança e é esta atmosfera acontecimental que assegura a necessidade do que pensamos.

Deixar-se visitar por encontros inesperados, movimentando-se em direção ao território do imprevisível, é possível quando nos permitimos estar abertos a escutar o que não imaginamos, o que não conhecemos, o que não queremos, aquilo em que não acreditamos, de que não necessitamos, que não apreciamos (LARROSA, 2007). O conceito de 'escuta', neste texto, refere-se a tudo o que lemos, ouvimos, visualizamos e assistimos.

A experiência da 'escuta', por vezes, oferece-nos uma dimensão de incerteza, pois não é possível antecipar o que obteremos em um encontro. Temos a tendência para desativar essas forças que nos colocam em situações de risco, sufocando nossos estranhamentos. Por isso, acabamos impedindo e neutralizando qualquer 'escuta' que venha a nos desacomodar. Buscamos uma variante 
de nós mesmos e, quando não encontramos, acabamos negando. Reduzir tudo à nossa imagem impede que nos aventuremos em direção ao desconhecido, contribuindo para que muitos encontros passem a não acontecer.

Deleuze (1988-1989, p. 13) explicita que "temos encontros com coisas, antes de tê-los com pessoas", pois os encontros podem acontecer de diversas formas, através de um filme, de uma carta, de uma poesia, de uma obra, de uma fotografia, de uma música: todos podem ter potência problematizadora, desestabilizadora e inventiva. Amplia-se, à vista disso, um leque de possibilidades, pois, nessa multiplicidade de encontros, singulares intercâmbios são realizados e inesperadas experiências são partilhadas, desafiando-nos a pensar provocativos arranjos e tessituras.

\section{Quando somos afetados pelos encontros}

Spinoza (2010), no livro Ética, explana que, quando somos afetados, nossa potência de agir pode ser expandida ou contida, incitando-nos ou não a pensar, a criar. Toda a potência é ativa e se encontra em ato, estando intrinsecamente relacionada com o poder de ser tocado pelo outro (pessoas, situações e coisas). Essa capacidade de ser afetado está invariavelmente ocupada por afecções que o efetuam (SPINOZA, 2010). Portanto, é possível afirmar que a potência é princípio de ação e também de estados de afecção. Ela não tem como ser definida de forma isolada, pois está envolvida no seio da natureza e é alterada por causas exteriores.

No livro 'Espinosa: filosofia prática', Deleuze (2002, p. 56) oferece de forma objetiva e clara a diferença entre afecção e afeto. Para o filósofo, o conceito de "afecção (affectio) remete a um estado do corpo afetado e implica a presença do corpo afetante, ao passo que o afeto (affectus) remete à transição de um estado a outro, tendo em conta a variação correlativa dos corpos afetantes".

A potência de agir, dessa forma, é o que possibilita o poder de ser tocado por uma infinidade de modos circundantes. Pela complexidade de suas afecções, o corpo humano passa a afetar o mundo e, também, a ser afetado por ele. Sua singularidade faz com que cada corpo disponha de uma potência específica, combatendo tudo o que possa minimizar ou extinguir suas forças.

O corpo não é, excepcionalmente, fruto inativo da coação de corpos exteriores, ele tende a resistir àquilo que o aniquila. Por isso, passa a ser relevante e vital para o corpo tudo o que venha a manter ou ampliar a potência de existir, pensar e agir.

Quando Spinoza (2010) nos lança a questão: 'o que pode um corpo?', ele nos convida a sermos investigadores de nós mesmos e também a percebermos a potência do nosso corpo quando efetivamente em ação. Pois, como indaga Chauí (2005, p. 75): "que é a filosofia espinosana senão o mais belo convite a perder o medo de viver em ato"?

Spinoza (2010, p. 221) argumenta que "homens diferentes podem ser afetados diferentemente por um só e mesmo objeto". Essa colocação nos impulsiona a pensar que o afeto não está submetido ao objeto, e sim implicado na atmosfera acontecimental de cada encontro, na capacidade própria que cada indivíduo possui de afetar e ser afetado pelas solicitações do presente.

Estar à espreita de encontros que tenham a capacidade de aumentar a nossa potência de agir instiga-nos a permanecer atentos às nossas experiências, observando quais encontros têm a capacidade de nos revigorar e quais têm a potência de nos cercear e debilitar. O desafio talvez esteja em saber tirar o melhor proveito dos afetos implicados neste campo de confluências, detendo-nos no quanto eles podem nos propelir à ampliação do leque de possibilidades do pensar, para, quem sabe, aumentar nossa potência de vida.

Spinoza (2010, p. 221) complementa dizendo que "um só e mesmo homem pode, em momentos diferentes, ser afetado diferentemente por um só e mesmo objeto". Os afetos que estão envolvidos em cada situação se alteram e se modificam, pois novas conexões são produzidas a todo instante.

Ao nos aproximarmos do mesmo objeto ou signos, não somos mais os mesmos que antes, pois, no 'entre' de um encontro, liames entraram em cena nesse emaranhado, outros afetos aconteceram e outras tessituras foram produzidas. Não acumulamos experiências, mas vamos produzindonos a cada experiência. Por mais que venhamos a convocar o encontro vivenciado, temos que levar em consideração que ele estará sendo atualizado pelos afetos do presente. Nesse caso, poderíamos dizer que nossos encontros estarão sempre sujeitos à contingência e à provisoriedade.

Hernández (2011, p. 31) expõe que não vê a "provisoriedade como uma carência, mas como uma constatação e uma possibilidade". Possibilidade de vivenciar outros encontros, de se movimentar em 
meio a outros afetos e de se reinventar a cada experiência. A provisoriedade pode ser o combustível dos nossos encontros, pois ela nos movimenta e nos faz cromatizar, impulsionando a produção e a extensão das nossas potências de agir e pensar.

Não se trata de experienciar encontros prontos e demarcados, mas encontros singulares e transitórios, sempre em vias de serem produzidos. Não se trata de ir à busca do nosso reconhecimento, da nossa essência, da nossa expressão identitária, mas de compreendermos que estamos em processo, em oscilação, em alteração, em variabilidade. Essa produção passageira, ziguezagueante e contínua, é o que nos faz abandonar as certezas que engessam e imobilizam, é o que nos mantém vivos e ativos, em processo contínuo de devir.

Conforme Deleuze e Parnet (1998, p. 10), "devir é jamais imitar, nem fazer como, nem ajustar-se a um modelo, seja ele de justiça ou de verdade. Não há um termo de onde se parte, nem um ao qual se chega ou se deve chegar". Devir não é requerer uma condição já criptografada, tampouco é conseguir chegar a uma posição predestinada, devir é um processo contínuo e inventivo.

Dessa forma, a partir da mobilização das diferentes experiências educativas ocorridas em 2012 e 2013, buscou-se neste texto dar atenção a alguns encontros compartilhados com as imagens fílmicas. Nestas vivências que experienciei enquanto docente em Artes Visuais, eu e os acadêmicos envolvidos procuramos pensar e problematizar a docência a partir de encontros com poesias, cartas, músicas e também com diferentes visualidades, como fotografias, desenhos, gravuras, grafite e intervenções. No entanto, a atenção dirigiuse às imagens cinematográficas, pois foram elas que mais tiveram potência de afetar e fomentar pensamentos em relação à docência.

A partir da experiência em assistir ao curtametragem 'Los colores de las flores' (com os acadêmicos do Curso de Graduação à Distância de Educação Especial - EAD - da Universidade Federal de Santa Maria - UFSM), ao longa-metragem 'A Invenção de Hugo Cabret' (assistido junto aos acadêmicos e supervisoras do Programa Institucional de Bolsa de Iniciação à Docência PIBID - das Artes Visuais da UFSM) e ao filme 'O Balão Branco' (com os acadêmicos da Graduação em Artes Visuais da UFSM, nas disciplinas de Estágio Supervisionado III e IV), foi possível tecer problematizações em relação a esses encontros e à docência, possibilitando a produção de diferentes disposições e tessituras.

Neste artigo, a intenção não foi em se ater às narrativas produzidas pelos acadêmicos nos encontros referidos, apesar delas estarem implicadas e terem atuado de forma intensa neste processo de pesquisa de doutorado. O foco, nesta escrita, foi explorar como o encontro com as imagens fílmicas, especialmente as infantis, puderam potencializar o pensar da atuação docente e o quanto tudo isso tem a possibilidade de afetar e nos produzir em meio à vida.

As imagens fílmicas infantis passaram a ser disparadoras do pensar, tendo a potência de nos arremessar a uma paisagem problematizadora. Não a imagem em si, mas a relação que se estabeleceu com a imagem e com as implicações do cenário circunstancial de cada encontro. Vale pontuar que a imagem é relação e por isso não se tem como pensar a imagem individualmente, pois ela é aliança.

Pensando no que foi exposto, buscou-se, neste texto, dar atenção ao que foi possível pensar e produzir com os três encontros fílmicos, atentando para que as experiências com os personagens infantis não servissem apenas como suporte reflexivo, mas que elas pudessem ser pensadas como propulsoras de inquietações em relação à atuação docente. Para tanto, a presença dos conceitos dos teóricos, especialmente os conceitos dos filósofos franceses Gilles Deleuze e Félix Guattari, tiveram a intenção de tensionamento quando operados junto às imagens fílmicas infantes e também quando coadunadas ao deslocamento e produção do pensamento de todos os envolvidos.

É neste emaranhado de relações que a potência inventiva para pensar outras vias para a docência pode acontecer e ressoar, colocando-nos em contato com o extraordinário, com o impensável, pois, no momento em que o pensamento é arrombado e provocado, hábitos do pensamento são contrariados e forçados a sair do seu estado apático e indiferente.

\section{Imagens fílmicas infantes que convocam a pensar}

Diversas experiências com imagens fílmicas aconteceram nos últimos semestres, porém as escolhas de pesquisa acabaram se direcionando naturalmente para filmes em que a criança tinha um papel importante nas cenas. A potência intensiva dos 'pequeninos' teve a capacidade de ressoar, disparando possibilidades e instigando o pensar.

Os estudos neste campo fizeram reafirmar 
que a intenção de aproximar a criança nesta investigação não está em infantilizar-se ou servir de modelo, mas em compor um espaço de incidência inventiva com a potência infante. É nesse sentido que, ao trazer o universo infantil para a discussão, o propósito não está em ser ou fazer como uma criança, mas pensar na relação intensiva de afetação com uma criança, que está muito além de qualquer sujeito criança, "que não é uma recordação, mas um bloco, um fragmento anônimo infinito, um devir sempre contemporâneo" (DELEUZE, 2006, p. 129). Um devir-criança, dessa forma, diz respeito à aliança, à proximidade e atração de forças moleculares que se reportam ao infantil, diferentemente da filliação que nos induz a uma representação molar.

A partir dos estudos de Deleuze e Guattari, Walter Kohan (2004, p. 64) comenta que

devir-criança é o encontro entre um adulto e uma criança - o artigo indefinido não marca ausência de determinação, mas a singularidade de um encontro não particular nem universal como expressão minoritária do ser humano, paralela a outros devires.

O que está em jogo é a intensidade de uma criança-mundo que de forma alguma se confunde com uma generalidade e totalidade, mas uma singularidade no mais elevado grau, uma potência intensiva, uma força viva.

É nesse sentido que a relação entre uma criança e um adulto pode trazer à tona um potente encontro, pois não se trata de uma reprodução ou de uma adaptação, mas sim de uma força de variação e de uma fenda aberta para a invenção, de um devircriança. É de forma a-histórica que um devir-criança habita, não está no passado saudoso e tampouco no amanhã idealizado, está nessa fenda, neste 'em meio', neste 'entre'.

As implicações fecundas produzidas com as imagens infantis dos filmes investigados oferecem a cada visitação uma pluralidade de sentidos. São imagens potentes que inquietam as convicções e interpretações corriqueiras, impelindo a explorar mais atentamente o que a aliança com uma criança pode instigar a pensar. Descortina-se nestas imagens uma infinidade de alternativas possíveis, pois elas nos convidam a movimentos imprevisíveis, paradas repentinas, silêncios constrangedores e criações ainda não imaginadas, expandindo as perspectivas do nosso panorama existencial.

Para uma maior compreensão será exposto um resumo do que trata cada um dos filmes trabalhados, salientando, também, quais personagens infantis estão imbricados.

O curta-metragem espanhol 'Los colores de las flores' (2011), da produtora Films Bosalay, com duração de quatro minutos, apresenta a história de um menino (Diego) que enfrenta o desafio de uma atividade escolar. Sua professora solicita que todos os estudantes da classe façam uma redação sobre as cores das flores. Sem o recurso da visão, Diego inventa uma lógica singular para se relacionar com a realidade e passa a criar significados para além das definições usuais e totalitárias.

Figura 1. Imagem do infante Diego no curta-metragem 'Los colores de las flores' (2011)

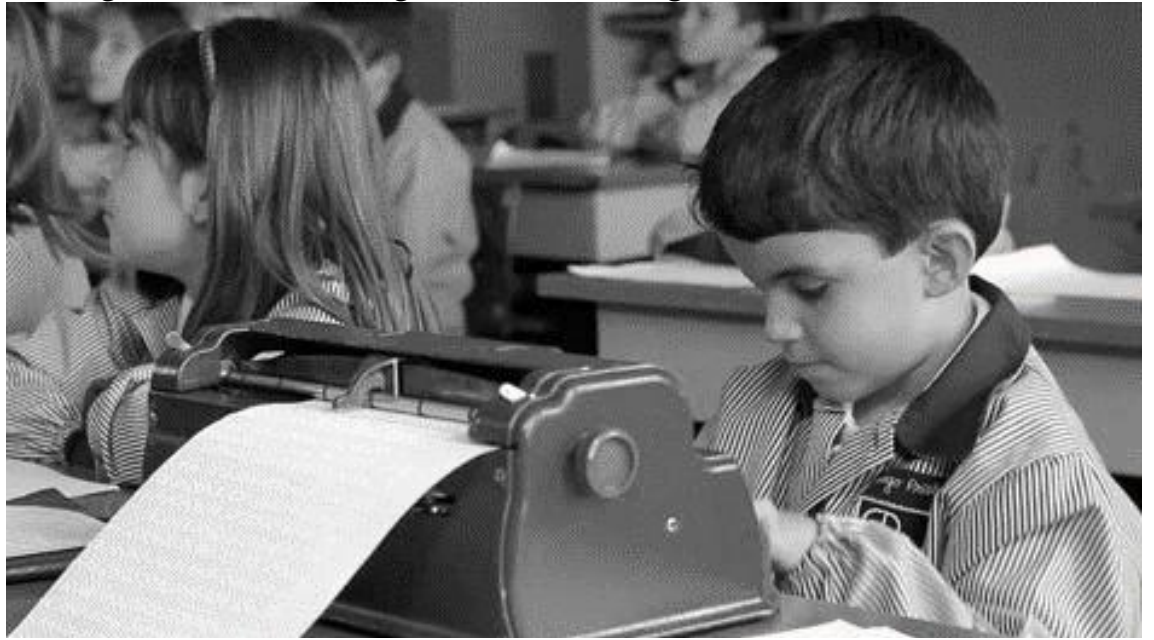

Fonte: Disponível em: http://www.tvanuncios.com/noticia-1120-once-los-colores-de-las-flores/

O longa-metragem 'A Invenção de Hugo Cabret' (2011) tem duração de duas horas e seis minutos e é baseado no livro homônimo de Brian Selznick. Com a direção de Martin 
Scorsese, o filme se passa em Paris, nos anos 30. Hugo Cabret é um menino de doze anos de idade, educado pelo pai, funcionário de um museu, que o levava sempre ao cinema. O pai de Hugo acaba morrendo em um incêndio, deixando para o menino uma espécie de robô que não funcionava, chamado de 'Autômato'. Após a morte de seu pai, Hugo é levado por um tio que o ensina a manter os relógios da estação de trem em funcionamento. Seu tio desaparece e Hugo fica vivendo nas dependências da estação, mantendo diariamente a rotina com os relógios. O garoto continua tentando consertar o robô, até que um dia conhece uma menina, Isabelle, que acaba se tornando sua grande amiga. Quando Hugo consegue terminar o robô, percebe que falta uma parte, uma chave em forma de coração. Ele leva Isabelle para conhecer o robô e descobre que ela possui a chave no seu colar, que se encaixa perfeitamente na fechadura existente no robô. Assim, Hugo, Isabelle e 'Autômato' se unem para solucionar o mistério.

Figura 2. Imagem dos infantes Hugo e Isabelle no longa-metragem 'A Invenção de Hugo Cabret' (2011)

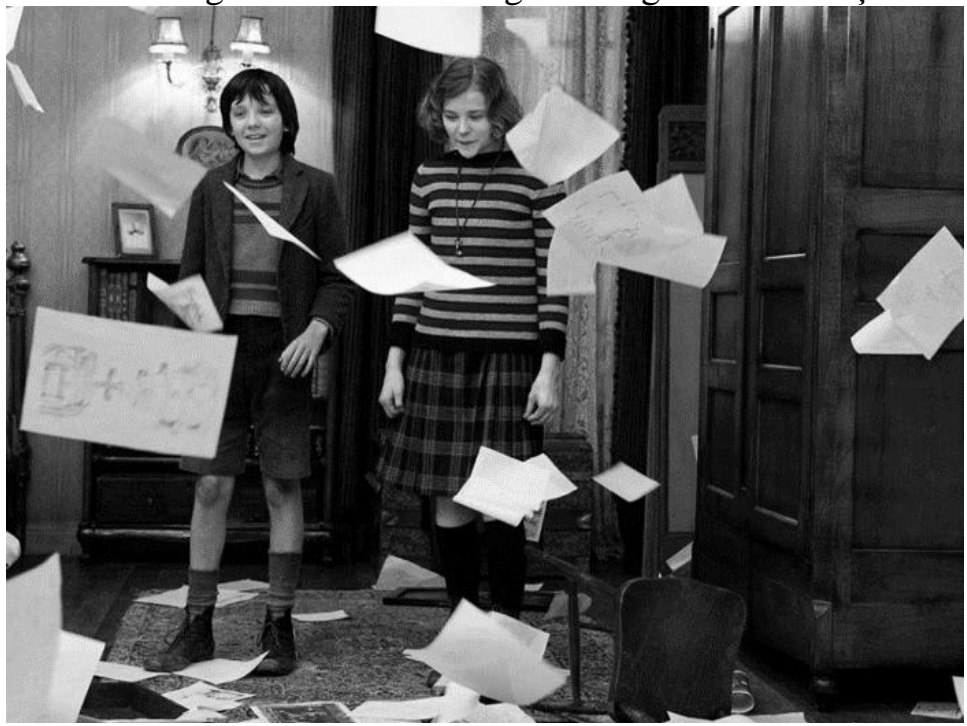

Fonte: Disponível em: http://cinemacompimenta.blogspot.com.br/2012/02/invecao-de-hugo-cabret.html

O filme 'O Balão Branco' (1995), com duração de 85 minutos, conta a história de uma menina chamada Razieh, que no decorrer das festividades do ano novo na Pérsia insiste para sua mãe the dar um lindo peixinho dourado e gordo. Como a família não possuía muitas posses, a mãe da garotinha nega seu pedido. $\mathrm{O}$ irmão, vendo a tristeza da irmã, resolve interceder junto a sua mãe, convencendo-a a dar o dinheiro para que ela pudesse comprar o tão desejado peixe. Razieh sai de casa com o dinheiro na mão em busca do seu peixe dourado e a partir desse momento passa a viver uma grande aventura durante o seu caminho até a loja. $\mathrm{O}$ que poderia ser um trajeto simples passa a ser um percurso repleto de paradas, obstáculos, frustrações, desafios e superações.

Figura 3. Imagem da infante Razieh no filme 'O Balão Branco' (1995). 


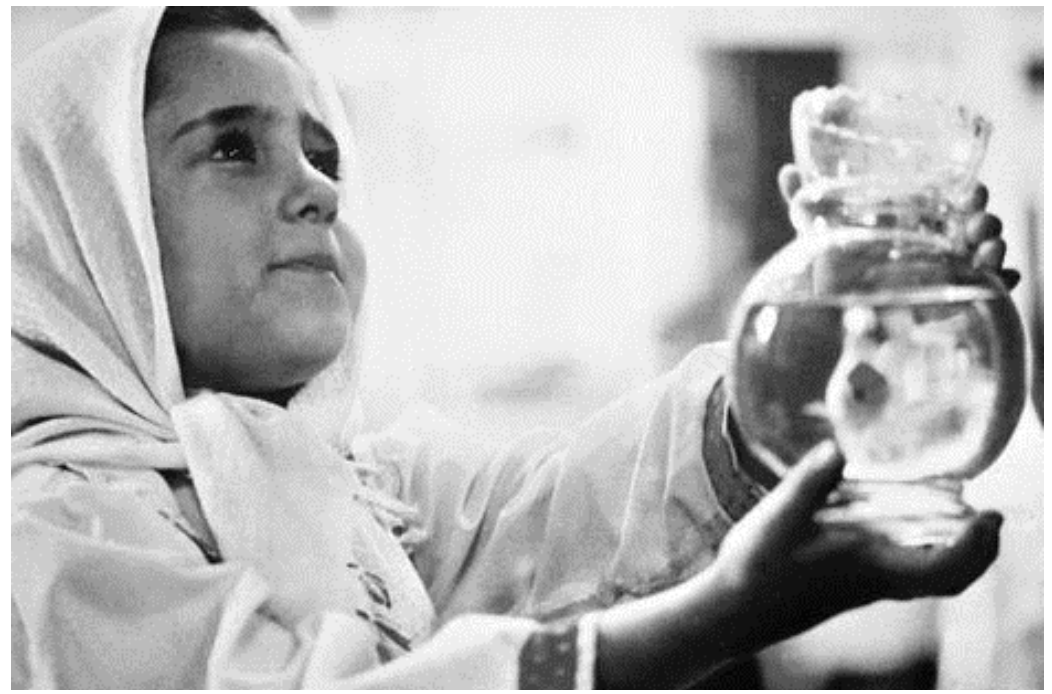

Fonte: Disponível em: http://javiuesse.com/2011/07/17/o-balao-branco-1995/

As relações com os infantes Diego, Hugo, Isabelle e Razieh, nos três filmes trabalhados, tiveram a potência de afetar, pois os atravessamentos incitados a partir dos encontros vivenciados com as crianças possibilitaram o pensar de outros desdobramentos, distanciando-se daquilo que era cognoscível, estável e imutável.

\section{Ao sermos atravessados pelos encontros com a infância}

O movimento de se deixar cruzar por vivências alheias, oportuniza obter um determinado afastamento do que estamos fazendo, passando a visualizar as situações e a nós mesmos sob outro prisma. Esses encontros podem propiciar o reconhecimento ou a aproximação de um 'quem' que talvez ofereça estratégias que alterem toda a situação e indiquem outras maneiras de pensar a própria vida.

Ao nos deslocarmos, somos convidados a experienciar com inusitados elementos, a compor outros arranjos, a pensar de forma diferente e a agir de outro modo. Em muitas situações, os atravessamentos propiciam que sejamos transferidos "de um lugar que não queremos estar por mais tempo (mas talvez nunca nos demos conta disso) a um lugar que queremos experimentar por um tempo (inclusive sem conhecermos com segurança o que há ou encontraremos alí) (ELLSWORTH, 2005, p. $50)$.

O processo falsificador, que pode ser fomentado pelas inusitadas experiências com as imagens fílmicas, incita à invenção de diferentes formas de pensar o mundo e também a própria vida.
Vamos constituindo-nos a cada encontro, revendonos nesta complexa rede de relações.

Essa façanha de deixar-nos performar no cenário educativo, requer estarmos atentos aos encontros que convenham e que possam compor conosco, fazendo acionar nossa potência de agir e pensar. A partir das relações e ligações de pensamento que estabelecemos, alianças e arranjos são criados, possibilitando a imersão de sentidos, por vezes, muito além do tempo-espaço em que foram produzidos.

Em um dilatado confronto de circunstâncias favoráveis e desfavoráveis, o encontro com os personagens infantis, dos três filmes referendados, passou a se atualizar junto ao vivido pelas formas de disposição e recombinação dos elementos. Essa atmosfera acontecimental contribuiu para que algumas incidências e considerações pudessem vir à cena e serem problematizadas.

Incidência 1

O encontro com o infante Diego, no filme 'Los colores de las flores', rouba-nos as certezas, pois introduz uma visão diferenciada da lógica costumeiramente esperada, faz relações que não supúnhamos existir e nos desafia a pensar nas diferentes possibilidades de se chegar a um resultado, mesmo que provisório. Ele potencializa o elemento da dúvida, ressalta a fragilidade perante o que se entende sobre as coisas e provoca a pensar no difícil movimento de desaprender o que já se aprendeu, aceitando a presença de outras verdades, além daquela que se acreditava ser única.

Diego, sem o recurso da visão, inventa outro conceito para as cores das flores, e acaba 
utilizando uma linha não reconhecível, uma linha não costumeira. Os corpos, diante de sua impossibilidade, criam linhas de fuga, deslocam-se por fluxos surpreendentes, desencadeando diferentes conexões e inventando algo incomum.

Deleuze e Guattari (2008, p. 78) advertem que as linhas de fuga não consistem "em fugir do mundo, mas antes em fazê-lo fugir, como se estoura um cano, e não há sistema social que não fuja/escape por todas as extremidades, mesmo se seus segmentos não param de se endurecer para vedar as linhas de fuga". Portanto, não se trata de escapar para fora de alguma coisa, mas de fazer escapar algo. Esse vazar é um ato de criação, pois novas linhas estarão sendo traçadas, uma insólita cartografia passa a ser concebida.

Por mais que se busque negar, as linhas de fuga sempre estarão lá, servindo de escape. "É evidente que a linha de fuga não vem depois, está sempre desde o início" (DELEUZE; GUATTARI, 2008, p. 79, grifo dos autores), pois a potencialidade da linha de fuga já se encontra lá, ao nível de virtualidade. São realidades, talvez, não visibilizadas, mas estão lá para serem utilizadas e inventadas a cada situação. Para obter a visibilidade das linhas de fuga parece ser potente se manter à espreita, ao modo animal, com o intuito de avistar e experienciar situações que eram imperceptíveis até então.

É na transversalidade da linha de fuga que encontramos uma nova forma de movimento, em que se tem acesso a múltiplas conexões, rompendo com a hierarquização e a progressão. Quando ligadas transversalmente, as coisas passam a corromper e livrar-se de sua aparência predefinida e esperada, irrompendo com as formas estabelecidas e abrindo inusitadas possibilidades de comunicação.

Necessitamos de todas as linhas para seguirmos vivos, não há linhas mais importantes que outras, todas nos compõem e passam a nos produzir. Entretanto, o desafio está em fazer com que as linhas de fuga elevem suas valências a cada vez que se conectarem com as outras linhas, ampliando a potência para fazerem escapar e escoar, compondo e criando o novo.

Pensando nessa linha de fuga que faz vazar e que engendra o novo, é oportuno recorrer novamente à experiência inusitada que o menino Diego vivenciou com a cor. Esse movimento inventivo nos instiga a pensar e a produzir alguns questionamentos: como lidamos com os desafios que aparentemente não estão ao nosso alcance? Como nos deixar tocar por aquilo que no primeiro momento não faz sentido para nós? Como se deixar afetar por aquilo a que não estamos habituados?

Privamo-nos de experienciar e pensar outras coisas quando estamos imunes a um cenário não costumeiro. O contexto conhecido passa a ser o nosso único campo de atuação, e por isso passamos, às vezes, a não perceber o que nos rodeia. Por não estarmos familiarizados com alguns signos, por não nos permitirmos uma experiência com eles, ou melhor, por não explorarmos o que o encontro com esses signos pode inaugurar, passamos a não experienciá-los.

Entretanto, é possível ampliar e problematizar um pouco mais essa discussão. Devido à segurança que um cenário corrente $\mathrm{e}$ habitual oferece, o corriqueiro passa, também, por vezes, a ser um empecilho, pois os encontros que estão naturalizados começam a não ser mais percebidos em todo seu horizonte de possibilidades. Como se deixar afetar por encontros que já estão naturalizados em nós? Por vezes, mesmo tendo o recurso da visão, ficamos cegos diante do que naturalizamos. Como permitir ao que naturalizamos, outras experiências que o modifiquem?

\section{Incidência 2}

O encontro com Hugo e Isabelle, no filme 'A Invenção de Hugo Cabret', viabilizou-nos a convivência com o falso e com o imaginário, instigando-nos a aproximação da possibilidade de atuar de maneira performática. A literatura e também o cinema se utilizam, a todo instante, da potência do falso, em que verdades permanentes são questionadas, possibilitando a problematização da verdade como 'modelo'. E nesta trama “o falsário não pode ser reduzido a um mero copiador, nem a um mentiroso, pois o que é falso não é apenas a cópia, mas já o modelo" (DELEUZE, 1990, p. 178).

$\mathrm{Na}$ experiência educativa, o diálogo com a potência do falso nas imagens fílmicas possibilita o questionamento do que é dado como verdade. Devido às narrações falsificadoras fugirem do sistema do juízo e do arbitramento, os envolvidos se sentem mais à vontade para pensar em outras alternativas, em outras possibilidades, em outras maneiras de viver. A verdade não necessita ser conhecida ou reconhecida, nem mesmo reprisada, precisa sim ser provocada e produzida, lembrando a todo momento que ela é e será sempre provisória.

Nietzsche diferencia a vontade de verdade e a vontade de potência. A vontade de verdade se baseia na convicção de uma verdade preexistente, 
enquanto a vontade de potência se apoia na ausência desse mundo: portando, cabe inventá-lo. Na vontade de potência, a potência "é o poder de afetar e de ser afetado, a relação de uma força com outras" (DELEUZE, 1990, p. 170).

Além de tocar e ser tocado, a vontade de potência consiste também em engendrar fabulações e inventar mundos onde qualquer possibilidade de julgamento é anulada. Estabelecer relações entre a vontade de potência e as potências do falso, na experiência educativa, possibilita pensar outros caminhos talvez ainda não trilhados, com a intenção de potencializar outras construções de sentido para a docência.

Uma ação de Hugo que merece destaque nessa incidência, foi quando ele passou a ser capturado por aquilo que parecia não ter mais serventia e pelas coisas diminutas encontradas em suas andanças na estação de trem. Essa atitude dele provoca-nos a pensar neste movimento de fazer macular o que foi sacralizado pelo tempo, interrompendo com os sentidos instituídos e inventando uma relação inusitada com 'as sobras', talvez incoerente e sem unicidade aos olhos de alguns.

Impelido pelas contingências do momento, Hugo compõe os elementos conforme a importância que dá às coisas e à sua manipulação particular. À vista disso, os destroços do cotidiano são recompostos de outra forma e passam a produzir outros sentidos. Novas forças são recrutadas para esses 'restos', potencializando-os de tal forma que outras funções são designadas para os mesmos.

Hugo rompe com as forças preestabelecidas impostas às coisas, às pessoas e às situações, violando a ordem dos itens encontrados e passando a reconfigurá-los de forma inusitada. Uma criança reinventa materiais, espaços e possibilidades de vida "pelo olhar que escapa, pelo movimento rítmico que pula e para, pelas sensações, pelas vertigens, pelo tempo, pelas formações e pelas deformações dos olhares, das ideias, (...), dos desejos" (LEITE, 2013, p. 60).

Exigir que os objetos de Hugo fossem abandonados ou organizados nos seus respectivos grupos de origem significaria exterminar a sua obra repleta de 'cacos de sentido'. A obra da vida não é produzida com um roteiro pré-definido, em que é imposto o que devemos ou não visualizar, capturar ou desprezar. A obra é realizada no percurso, com surpresas e apreensões inesperadas. Quem sabe venhamos a nos surpreender com aquilo que nos parecia não servir mais? Aquelas asas quebradas do cavalo alado do sobrinho... Recolhidas ao chão... Quem sabe não são elas que nos fazem voar?

Incidência 3

O desassossego e a inquietude evidenciados por Razieh, no filme 'O Balão Branco', durante o percurso, colocam em questão os lugares que prescrevemos para a infância, fazendo-nos pensar na presunção que temos em estabelecer que a criança ocupe somente os espaços molares, constrangendo-as a ter sua morada em temporalidades progressivas e a movimentar-se de forma que contemple os pontos já fixados anteriormente pelo adulto. A personagem Razieh traz para a discussão a possibilidade de haver uma infância que

(...) habita outra temporalidade, outras linhas: a infância minoritária. Essa é a infância como experiência, como acontecimento, como ruptura da história, como revolução, como resistência e como criação. É a infância que interrompe a história, que se encontra num devir minoritário, numa linha de fuga, num detalhe; a infância que resiste aos movimentos concêntricos, arborizados, totalizantes (...). É a infância como intensidade, um situar-se intensivo no mundo; um sair sempre do 'seu' lugar e se situar em outros lugares, desconhecidos, inusitados, inesperados (KOHAN, 2007, p. 94-95, grifo do autor).

O desejo de ter o peixe de aquário, a relação com os encantadores de serpentes, a procura do dinheiro, a experiência com a vara do vendedor de balões e com a goma de mascar, a presença dos doces nos bolsos do vestido e o contato com o balão branco apresentam-nos uma forma autêntica das crianças se conectarem com as coisas, com as pessoas e com as situações. Elas estão sempre a nos abismar. Por mais que almejemos ter a pretensão de colocá-las em determinadas posições e lugares, elas estão sempre a esquivar-se. Por mais que venhamos a ditar significados e utilidades às coisas, outras funções são oferecidas pelas crianças.

Os infantes apresentam um olhar do cotidiano que pode ser desdobrado e estendido em múltiplos sentidos. Isso é possível quando o olhar não é linear, quando leva em consideração a ótica das possíveis escolhas, estando à mercê da vida em sua pluralidade e em sua força de variação. É a polifonia de seu mundo que os instiga a inventar outras possibilidades no mundo em que vivem. 
Os singelos sorrisos e o prazer intenso ao mascar a goma em meio às aflições fazem com que Razieh, seu irmão e o vendedor de balões passem a olvidar, mesmo que momentaneamente, a problemática que os vinculou. As crianças do filme oferecem alguns indícios de como é possível esquecer as tensões do dia a dia e ter alegria em meio às dificuldades e desafios. Elas nos incitam a pensar numa experiência docente prazerosa, na possibilidade de fazer os nossos momentos menos pesados, menos sofridos, mais leves e mais alegres.

As crianças também nos instigam a pensar na potência de viver o hoje, sem a inquietação com o amanhã. A não preocupação com as consequências permite que as crianças vivam intensamente o momento, sem contenções $\mathrm{e}$ apreensões futuras. Talvez isso se deva ao não conhecimento das possíveis implicações e resultados de uma situação, fazendo com que elas se entreguem mais ao que cada circunstância pode oferecer. Deixam-se arrebatar pelos signos improváveis que, possivelmente, para nós adultos não seriam nem considerados, devido às experiências anteriores e às aflições antecipadas que impomos aos signos.

Talvez por ainda não estar impregnada com condutas que engessam e paralisam, Razieh se deixa atravessar pela novidade do trajeto, reinventando-se e se produzindo a todo instante. A autenticidade está no semblante da menina, pois não sabe dizer sim quando quer dizer não. A espontaneidade prepondera, uma vez que ainda não aprendeu a mentir para os outros e nem para si mesma.

Este encontro fez disparar questionamentos sobre a prática docente, abrindo um abismo entre as limitações que por vezes impomos ao trajeto e a gama de possibilidades que são oferecidas ao percorrê-lo. Ao nos colocar frente a frente com a presunção de planificar percursos e idealizar comportamentos, passamos a perceber que as experiências mais significativas acontecem distantes dos limites que lhes prescrevemos.

Incidência 4

Junto de Diego, Hugo, Isabelle e Razieh foi possível viver intensamente os encontros com as pessoas, as situações e as coisas que surgiram no percurso. $\mathrm{O}$ imprevisto do trajeto passou a nos desafiar a viver experiências desconhecidas, deixando-nos afetar pelos peixinhos dourados, pelas flores, pelas sobras e cacos recolhidos na estação de trem, pelo canto dos pássaros, pelas serpentes e pelos balões.

As crianças dos filmes também nos instigaram a entrar em contado com a coragem e a ousadia, permitindo que viéssemos a pensar o impensável, não ter receio do absurdo e do inimaginável. Juntamente com elas, foi possível ensaiar possibilidades, rever conceitos, apostar em algumas paradas e caminhos e a fabular infinitas possibilidades de viver a vida.

Apesar das limitações físicas, das perdas afetivas, das dificuldades materiais e dos momentos negativos que os infantes experienciaram nos filmes, todos demonstram enxergar outras possibilidades na superfície cotidiana. Acreditar na vida, no mundo é o que mais necessitamos na docência, para que possamos pensar no impossível e no impensável. Na opinião de Deleuze (2010, p. 222), "acreditar no mundo significa principalmente suscitar acontecimentos, mesmo pequenos, que escapem ao controle, ou engendrar novos espaçostempos, mesmo de superfície ou volume reduzidos".

Por acreditarem no mundo, as crianças nos filmes criaram possibilidades de vida, cada uma a seu modo, envolvidas nas contingências do momento. Como observa Deleuze (2010, p. 183), "criar não é comunicar mas resistir", é crer que é possível fazer algo, é inventar outras vias no seu campo de atuação, é investir em linhas de fuga, pois ao fazer isso traímos as significações hegemônicas e criamos sentidos e potências de vida.

Não precisamos aguardar que as grandes rupturas nos cheguem prontas, elas podem acontecer no âmbito da educação menor. Cada um de nós pode resistir, atuando no cenário que nos compete e com as ferramentas de que dispomos no momento, fazendo operar humildes mudanças.

Desistir é o caminho mais fácil, difícil é permanecer. A decisão de permanência e de sobrevivência, por vezes, é também um ato de resistência. A diferença se encontra em como iremos atuar nesse espaço, mesmo que pequeno. Talvez não consigamos arrombar portas ou destrancá-las, mas podemos produzir pequenas frestas a partir das quais o sopro de ar benfazejo nos envolva e nos renove. No contexto escolar é possível inventar brechas, através das quais professores e estudantes aproveitem esses espaços para deixar a brisa passar, reconstruindo suas próprias histórias.

Quem sabe o cinema, por ser um campo de experimentações do pensar, possa ser uma dessas fendas em que o ar renovador flua, deslize e dissipe, pois, através das suas imagens e signos, faz 
movimentar mundos que pareciam inviáveis, investindo em outras vias e possibilidades de vida.

Deleuze (2010, p. 80) coloca que "o cinema é produtor de realidade". A experiência ao assistir a um filme é real, pois as cenas e as sensações são mostradas de forma que venhamos a sentir e vivenciar intensamente cada momento. Passamos a fazer parte do filme, acrescentando outros fatos e inventando outras tramas.

O cinema, por nos incitar e nos colocar em condições de ficcionar junto com os personagens, propicia que ampliemos as perspectivas do nosso cenário existencial, passando a crer que mundos inimagináveis são possíveis.

Machado (2010, p. 288) reforça esta questão, expondo que

o liame do homem e do mundo é o impossível, o impensável que só pode ser objeto de crença. E se apenas a crença no mundo pode religar o homem que perdeu a capacidade de reação ao que ele vê e ouve, o poder do cinema moderno é dar novamente ao homem a crença no mundo. Com o cinema moderno é possível acreditar nesse liame como no impensável que precisa ser pensado - crença que faz do impensado a potência própria do pensamento; é possível servir-se da impotência do pensamento para acreditar na vida.

É neste sentido que os encontros com as imagens das crianças, nos três filmes, convocamnos a pensar sobre a capacidade que elas dispõem para vivenciar intensamente a potência do impensado do pensamento, pois, como afirma Millôr Fernandes, "uma criança está deixando de ser criança no dia em que começa a fazer perguntas que têm respostas". 1

\section{Considerações de alguns pontos, sem final...}

Nos encontros com os filmes 'Los colores de las flores', 'A Invenção de Hugo Cabret' e 'O Balão Branco', os infantes tiveram a potência de afetar e movimentar fluxos de pensamentos, impondo-se de forma inusitada, distintas das posições costumeiramente prescritas.

Essa experiência com os 'pequeninos' incitou a fazer insólitos diálogos com a própria vida e a produzir outros campos de sentido em relação à experiência docente. Provocou, também, a pensar que a incidência inventiva da potência infante pode contribuir na composição de um novo cenário, instigando a olhar com atenção para questões que estão naturalizadas na prática educativa, examinando nossas escolhas, ações e - porque não a nós mesmos. A relação com as crianças, nas imagens fílmicas pesquisadas, potencializou o esboço de outras possibilidades de atuar, simulando diferentes modos de ser e ficcionando singulares formas de vivenciar a docência.

Permanentemente somos testados, pois inúmeras são as ocasiões em que nos deparamos com a nossa fragilidade, quando insistimos em repetir falas decoradas, representar papéis conhecidos, executar movimentos milimetricamente planejados e optar por roteiros concluídos. Reconhecer essas situações, permitindo que venham à tona, já é um passo importante para que se possa, quem sabe, lidar melhor com elas.

Entretanto, além desse movimento, é necessário também o confronto com as nossas limitações, tendo o desejo de colocar em 'xeque' as convicções confortadoras, de convulsionar a nossa alma, para, quiçá, alforriar o pensamento e deixá-lo se refazer e se reinventar.

O desafio é constante na experiência educativa, pois requer coragem em inventar diferentes cenários e roteiros a cada estreia, mudar os scripts conforme as contingências de cada cena, oferecer espaços para a improvisação e ficcionar tantos finais quantos forem possíveis.

Nota
$1 \underset{\text { http://kdfrases.com/frase/146962. }}{\text { Frase }}$

\section{Referências}

CHAUÍ, M. Espinosa: uma filosofia da liberdade. São Paulo: Moderna, 2005.

DELEUZE, G. O Abecedário de Gilles Deleuze. Realização de Pierre-André Boutang, produzido pelas Éditions Montparnasse, Paris. No Brasil, foi divulgado pela TV Escola, Ministério da Educação. Tradução e Legendas: Raccord [com modificações]. A série de entrevistas, feita por Claire Parnet, foi filmada nos anos 1988-1989.

Cinema 2 - A imagem-tempo [tradução de Eloisa de Araújo Ribeiro]. São Paulo: Brasiliense, 1990.

Espinosa: filosofia prática. [tradução de Daniel 
Lins e Fabien Pascal Lins]. São Paulo: Escuta, 2002.

DELEUZE, G. Crítica e Clínica [tradução de Peter Pál Pelbart]. $2^{\mathrm{a}}$ reimpressão. São Paulo: Editora 34, 2006.

\section{Conversações [tradução de Peter Pál}

Pelbart]. 2. ed. São Paulo: Ed. 34, 2010.

DELEUZE, G; GUATTARI, F. Mil platôs: Capitalismo e esquizofrenia, v. 3 [tradução de Aurélio Guerra Neto et al]. $4^{a}$ reimpressão. São Paulo: Ed. 34, 2008.

DELEUZE, G; PARNET, C. Diálogos. [tradução: Eloisa Araújo Ribeiro]. São Paulo: Escuta, 1998.

ELLSWORTH, E. Posiciones en la enseñanza: diferencia, pedagogía y el poder de la direccionalidad. Akal: Madrid, 2005.

HERNÁNDEZ, F. A cultura visual como um convite à deslocalização do olhar e ao reposicionamento do sujeito. In: MARTINS, R; TOURINHO; I. (Orgs.) Educação da cultura visual: conceitos e contextos. Santa Maria: Ed. UFSM, 2011. p. 31-49.

KOHAN, W. A infância da educação: o conceito devir-criança. In: KOHAN, W. (Org.) Lugares da infância: filosofia. Rio de Janeiro: DP\&A, 2004. p. 51-68.

Infância, estrangeiridade e ignorância Ensaios de filosofia e educação Belo Horizonte: Autêntica, 2007.
LARROSA, J. Literatura, experiência e formação. In: COSTA, M. V. (Org.) Caminhos investigativos I: novos olhares na pesquisa em educação. 3. ed. Rio de Janeiro: Lamparina editora, 2007. p. 129156.

LEITE, C. D. P. Infância, brinquedo e linguagens: entre recortes e montagens. Revista Sul-Americana de Filosofia e Educação. n. 20, p. 45-63, maioout/2013.

MACHADO, R. Deleuze, a arte e a filosofia. 2.ed, Rio de Janeiro: Jorge Zahar Ed., 2010.

SPINOZA, B. de. Ética [tradução e notas de Tomaz Tadeu]. 3.ed. Belo Horizonte: Autêntica, 2010.

VAN MANEN, M. Investigación educativa y experiencia vivida. Barcelona: Idea Books, 2003.

\section{Filmografia}

A INVENÇÃO de Hugo Cabret. Direção de Martin Scorsese. Estados Unidos, 2011. Disponível em: http://www.saudadeeadeus.com.br/filme415.htm.

Acesso em: 13 dez. 2012.

LOS COLORES de las flores. Produtora Films Bosalay. Espanha, 2011. Disponível em: https://www.youtube.com/watch?v=BhheUpOB640. Acesso em: 20 ago. 2012.

O BALÃO Branco. Direção de Jafar Panahi. Irã, $1995 . \quad$ Disponível em: https://www.youtube.com/watch?v=_3k7sKDZTtk. Acesso em: 30 maio 2013.

\section{Sobre as autoras}

Vivien Kelling Cardonetti é Doutora em Educação pela Universidade Federal de Santa Maria - UFSM - RS; pesquisadora do Grupo de Estudos e Pesquisas em Arte, Educação e Cultura - GEPAEC/ UFSM vinculado ao CNPQ; Pós-Doutoranda junto ao Programa de Pós-Graduação em Educação, na Linha de Pesquisa Educação e Artes, na Universidade Federal de Santa Maria - UFSM - RS.

Marilda Oliveira de Oliveira é Professora Associada IV do Programa de Pós-Graduação em Educação com orientações de mestrado e doutorado na Linha de Pesquisa Educação e Artes. Coordenadora do Grupo de Pesquisa GEPAEC - Grupo de Estudos e Pesquisas em Arte, Educação e Cultura, cadastrado na plataforma do CNPq. Editora da Revista Digital do Laboratório de Artes Visuais, UFSM, RS.

Recebido em janeiro de 2016.

Aprovado em dezembro de 2016. 